\title{
Vertical Violence Among Faculty Nursing Students Experienced in Health Care Settings During Their Clinical Learning.
}

\author{
Fatma M. Elemary ${ }^{1}$, Samia A. EL Nagar ${ }^{2}$ \\ ${ }^{1}$ Assistant Professor, Psychiatric-Mental Health Nursing, Ain Shams University, Egypt. \\ ${ }^{2}$ Assistant Professor, Pediatric Nursing, El-Menoufya University, Egypt. \\ ${ }^{2}$ Currently in Jazan University, KSA. \\ Corresponding E-mail samiamansour901@yahoo.com
}

\begin{abstract}
Background: Nursing students are exposed to violence in health care setting during their clinical training.

Aim: The study aims to investigate to vertical violence encountered by the nursing students throughout their clinical learning in health care settings.

Design: descriptive study was utilized

Setting: This study was conducted at nursing college and allied health sciences, Jazan University, KSA. Subjects: The sample of convenience consisted of 95 students from $3^{\text {rd }}$ and $4^{\text {th }}$ grade.

Tools: The following instruments were utilized: 1) Characteristics of student nurses and their violence sheet;2) Negative Acts Questionnaire; and The Bullying Student Nurse Questionnaire.

Findings nearly half of the studied nursing students were encountered to violence during their clinic course for two to three times due to their lack of effective communication skills. With high frequency of exposure to negative acts as assignments, task, work or rotation responsibilities made for punishment rather than educational purposes, threats of violence or physical abuse or actual abuse and being ignored and excluded or socially isolated. Also; with high frequency of exposure to bullying behaviors as threats of physical violence, inappropriate jokes were made about me and teased. However, there were not significant correlation between assignments, task, threats of physical violence and academic achievements of the participants. Recommendations: The nursing students must be prepared efficiently before they attend clinical environment. Beside, continuous presence \& supervision, of clinical instructors, where support and positive reinforcement is provided for the nursing students in a nonthreatening clinical environment.
\end{abstract}

Key Words: Vertical Violence, Nursing Student .Clinical Learning.

\section{Introduction}

Violence is a phenomenon that is prevalent in the nursing profession. Research has revealed a variety of negative peer-to-peer behaviors that lower morale and lead to turnover. Violence occurring between individuals with unequal power, such as staff nurse and student nurse. (1) For many years in nursing, a negative phrase has been his circulated throughout literature to indicate that while we care for patients, we may not care for our new colleagues. This phrase indicates that nursing eats their young. (2) The nursing students that will be our future in health care by staff nurses already in practice. This denotes a pattern of behavior from higher level of functioning to a lower level which indicates vertical

violence. (3)

Nurse - to- nurse horizontal violence includes deliberate, unwanted or unwarranted behavior bestowed by one nurse coworker towards another with the intent to hurt, manipulate, degrade, sabotage, or isolate. Recent studies indicate that nurse -to- nurse violence is widespread. In a survey at a large medical center $65 \%$ of respondents reported that they frequently observed lateral violence between among coworkers. (4)

Vertical violence is as any act of violence such as yelling, snide comments, with holding, pertinent information, and rude ignoring and humiliating behaviors which transcends between two or more persons on different levels of the hierarchical systems and prohibits professional performance or satisfaction in the work environment. Also vertical violence can include any type of negative behavior used by a person in a superior position that somehow causes feeling of degradation in another person that is in an inferior position in the organizational hierarchical chain. $(5,6)$

Violence behaviors can be an obvious act or a covert act, such as denying requests or overloading assignments. Student's nurses who are exposed to vertical violence may experience physical and psychological effects. Feeling of self-doubt, inadequacies', depression, increased stress and anger can surface in the victim after just one received violent behavior. (7)

Nursing students are not exempt from these negative behaviors, during their clinical placements, students are at increased risk for experiencing vertical violence from staff nurses. This can include any number 
of negative behaviors that may be a detriment to a student's learning, student nurses feel powerless at the bottom of the hierarchical chain. (8)

Nurse leaders must be aware of violent behaviors and take a chief position in leading the efforts to reduce the incidence of vertical violence.

Transformational leadership theory is one such theory that can promote higher levels of moral and ethical behaviors in followers as well as functioning and an individual desire to succeed for staff and organization therefore if nursing leadership is positive, it is believed that this theory can assist student nurses as well as neophyte nurses in the development of positive professional identity. (9)

Vertical violence is a term used to describe the way a senior colleague behaves toward a subordinate. In the clinical setting, many trainee nurses and new graduate nurses may feel embarrassed, intimidated, and humiliated by their teachers, doctors, or more senior colleagues. (10)

\section{Significance of the study:}

Violence in health care institutions is a common problem in the world.Vertical violence encountered by the students throughout their training in health care settings is a significant concern as it negatively affects the quality of learning $\&$ academic performance and causes the students to have a negative perception of nursing as a profession. The common point of studies on violence against health care workers is that violence in the health field is more than other work places and it is less taken into account. The incidence of violent episodes is now recognized as a major health priority by the World Health Organization, the International Council of Nurses, and Public Services International. Nonetheless, workplace violence toward nurses has continued to rise (11). Therefore, it is a professional and ethical responsibility to be aware and facilitate change to stop the cycle of violence in order to improve the students' educational experience prior to entering a workforce in which violence has been well documented. For that reason; it is important to investigate vertical violence that is experienced by the nursing students throughout their clinical training.

Aim of the study: is to investigate vertical violence encountered by the nursing students throughout their clinical learning in health care settings.

\section{Research question:}

The primary research question for this study was: Are the nursing students perceive and experience vertical violence in health care settings during their clinical learning?

\section{Subjects And Methods}

A .Study design: A descriptive study was utilized to conduct this study,

B. Participants \&Settings: The data of the study were obtained from (95) participated undergraduate nursing students of 3rd and 4th grades whereas, the first and second grade students are not included in the scope of the study because they have not started to gain clinical experience yet.

The inclusion criteria for the participants were:

-They had to be willing to participate in the study

- There was no age limitation

\section{Tools of data collection:}

Three different tools were used for the purpose of data collection: These include a Characteristics of student nurses and their violence sheet; Negative Acts Questionnaire and The Bullying Student Nurse Questionnaire.

1- Characteristics of student nurses and their violence sheet: It was developed by researchers and includes the characteristics of the student nurses as academic year, academic average, period of training, place of training and type of hospital. In addition to characteristics of student nurses' violence encounters as frequency of exposure to violence during their clinic course, person who inflicting violence, reasons for subjecting to violence.

2-Negative Acts Questionnaire: To identify vertical violence among students nurses throughout clinic course training, we used a short version of the Negative Acts Questionnaire that adapted according to the earlier studies on bullying against nursing students particularly those conducted by $(\mathbf{1 2 , 1 3 )}$. The scale consists of thirteen items referring to personal related bullying (e.g., being shouted, spreading gossip, socially isolated), work related bullying (e.g., unmanageable workloads, hostility after or failure to acknowledge significant clinical or academic accomplishment), and physical intimidating forms of bullying (e.g., threats of violence or physical abuse, intimidating behavior such as finger pointing). The scale which had already been translated and validated in previous studies. $(\mathbf{1 3}, \mathbf{1 4})$ and the Cronbach alpha coefficient of the scale in this study was $>0.80$. Therefore, it is accepted that a short version of the Negative Acts Questionnaire as reliable and used it in statistical 
analyses. The respondents are asked how often they have been exposed to the specific behavior with response categories are "Not frequently", "Frequently", "High frequently".

3-The Bullying Student Nurse Questionnaire, developed by (15).was used to investigate student nurses' experiences of violence. It comprises 26 statements associated with the phenomenon of bullying, on which students are asked to indicate behavior frequency. The respondents are asked how often they have been exposed to the specific behavior with response categories are "Not frequently", "Frequently", "High frequently".

\section{Ethical considerations:}

The purpose of the study was explained to each student and oral consent to participate in the study was obtained from them. Confidentiality and anonymity of participants; as well as their right to withdraw from the research at any time were ensured. Data was collected through self-administered questionnaires that were distributed among the subjects at clinical settings to encourage full students' participation. The questionnaires took approximately from 15 to 20 minutes/student. The data was collected for a period of 4 months started from the February to May 2016 .

\section{Results}

First section: Characteristics of the studied participants and their violence encounters.

Figure (1) Distribution of the students in academic year

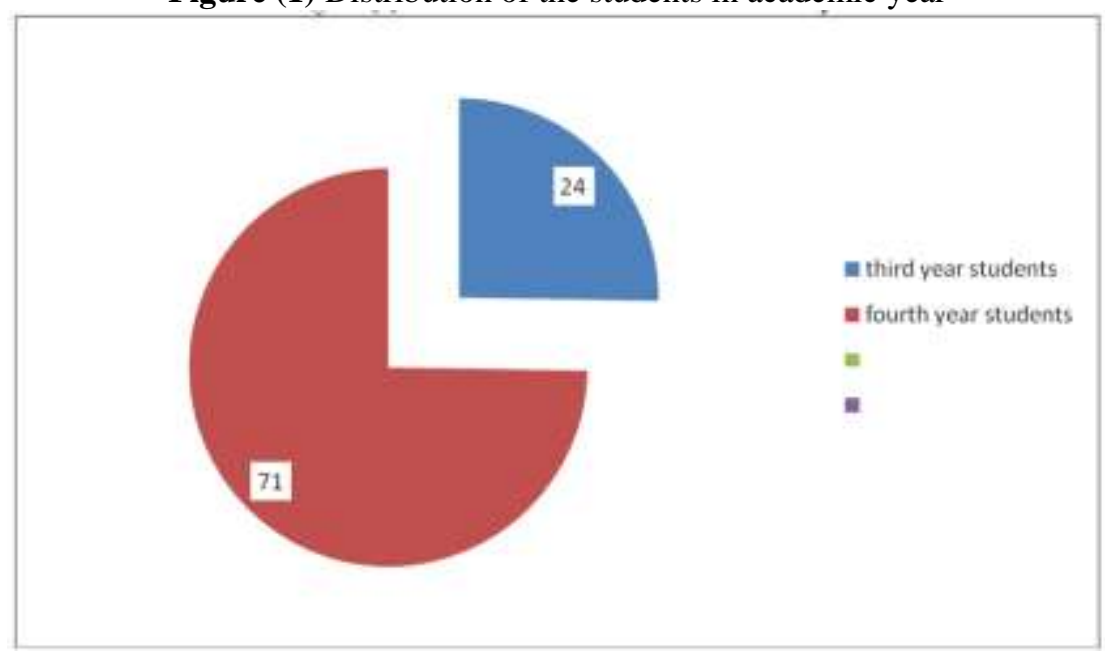

Figure (1) indicated that the studied students were at the fourth grade $71 \%$ and $24 \%$ were at the third grade.

Figure (2) Academic average of students

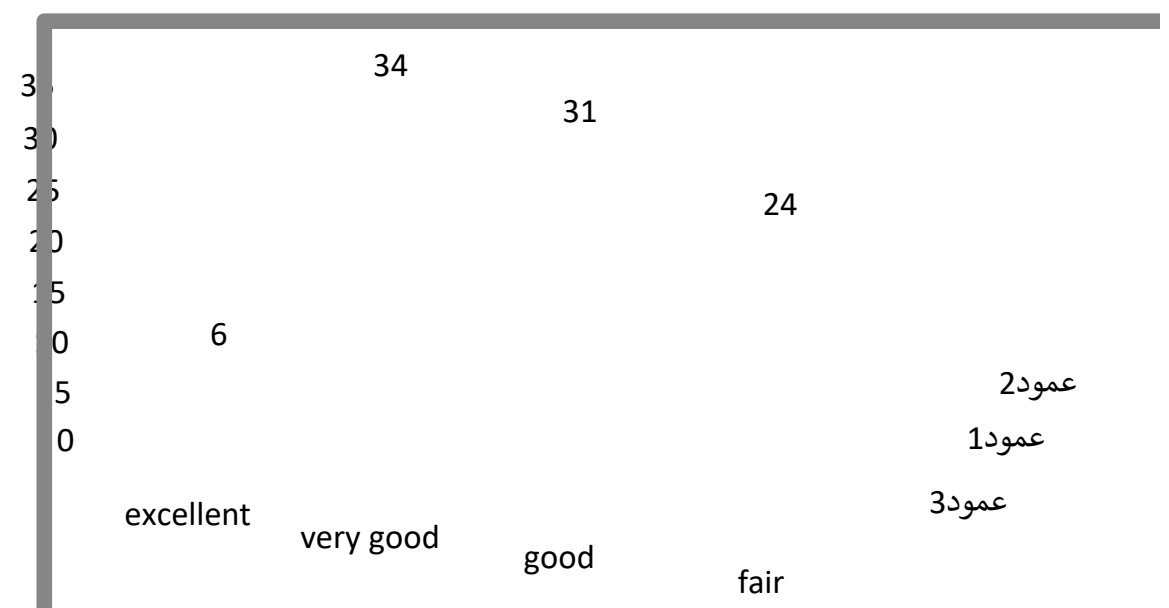

Figure (2) Showed that the academic average of students were between very good and good $34 \%$ and $31 \%$ respectively while $24 \%$ of them were fair. 
Figure (3) training period in months

$\begin{array}{rrrrrrr}60 & & & 50 & & & \\ 40 & & & & & & \\ 20 & 4 & 14 & & 11 & 13 & 3 \\ 0 & & & & & & \\ & 0 & 1 & 2 & 3 & 4 & 5\end{array}$

Regarding training periods of students, it was found from Figure (3) 50\% of them the period was two months while $14 \%$ and $13 \%$ were trained one to four months respectively.

Table (1) Characteristics of studied nurses student's for violence encounter during their clinic course work

\begin{tabular}{|l|l|l|}
\hline Characteristics & Study subjects (N= 95) \\
\cline { 2 - 3 } & No & \% \\
\hline Place of training & 6 & 6.3 \\
Emergency department & 27 & 28.4 \\
Medical surgical departments & 55 & 57.9 \\
Pediatric unit & 7 & 7.4 \\
ICU & & \\
\hline Type of hospital & 29 & 30.5 \\
Governmental & 66 & 69.5 \\
\hline Private & & \\
\hline Frequency of exposure to violence during the period of training & 3.1 \\
once & 43 & 45.3 \\
Twice. & 43 & 45.3 \\
Three times & 6 & 6.3 \\
\hline Four times or more & $1.55 \pm 0.66$ & \\
\hline Mean \pm DS & 3 & 3.2 \\
\hline Person who inflecting violence & 3 & 27.4 \\
Clinical instructor & 26 & 56.8 \\
Nurse. & 54 & 12.6 \\
Physician & 12 & \\
Others & & 10.5 \\
\hline Reason for subjected to violence & \\
Lack of confidence in nursing student from the patient, patient's family and clinical staff. & 10 & 52.6 \\
Nursing student's lack of effective communication skills with others. & 50 & 26.3 \\
Nursing student's lack of knowledge and skills in care giving. & 25 & 5.3 \\
Being negatively affected by media & 5 & 5.3 \\
Lack of sufficient time allocated to the patient & 5 & \\
\hline
\end{tabular}

Table (1) shows that; $57.9 \%$ of students were trained in Pediatric unit in private hospitals. While the frequency of exposure to violence during the period of training were two to three times $45.3 \%$.In addition the person who inflecting violence were physician $56.8 \%$ while the reason for subjected to violence was nursing student's lack of effective communication skills with others $52.6 \%$.

Second section: Frequency of exposures to negative acts as experienced by the studied student nurses.

Table (2): Distribution of studied nurses student's according to their frequency of exposures to negative acts.

\begin{tabular}{|c|c|c|c|c|c|c|c|c|}
\hline \multirow[t]{3}{*}{ Reported Negative Acts } & \multicolumn{6}{|c|}{ Nursing students $(\mathrm{N}=95)$} & \multirow{3}{*}{$\begin{array}{l}\text { Chi- } \\
\text { square }\end{array}$} & \multirow[t]{3}{*}{ p-value } \\
\hline & \multicolumn{2}{|c|}{ Not frequent } & \multicolumn{2}{|c|}{ Frequent } & \multicolumn{2}{|c|}{ Highly frequent } & & \\
\hline & No. & $\%$ & No. & $\%$ & No. & $\%$ & & \\
\hline $\begin{array}{l}\text { 1-Being shouted at or being the target of spontaneous anger } \\
\text { (or rage) }\end{array}$ & 83 & 87.4 & 12 & 12.6 & 0 & 0 & 48.5 & $.000^{* *}$ \\
\hline 2-Inappropriate, nasty, rude or hostile behavior & 85 & 89.5 & 10 & 10.5 & 0 & 0 & 18.6 & $.000 * *$ \\
\hline 3-Belittling or humiliating behavior & 77 & 81.1 & 8 & 8.4 & 10 & 10.5 & 88.3 & $.000^{* *}$ \\
\hline
\end{tabular}




\begin{tabular}{|c|c|c|c|c|c|c|c|c|}
\hline 4-Spreading of gossip and rumors about you & 90 & 94.7 & 5 & 5.3 & 0 & 0 & 101.8 & $.000 * *$ \\
\hline 5-Cursing and swearing & 90 & 94.7 & 5 & 5.3 & 0 & 0 & 56.5 & $.000 * *$ \\
\hline $\begin{array}{l}\text { 6-Negative and disparaging remarks about nursing's } \\
\text { profession }\end{array}$ & 95 & 100 & 0 & 0 & 0 & 0 & 1.7 & .43 \\
\hline $\begin{array}{l}\text { 7-Assignments, task, work or rotation responsibilities made } \\
\text { for punishment rather than educational purposes }\end{array}$ & 26 & 27.4 & 3 & 3.2 & 66 & 69.5 & 6.9 & $.032 *$ \\
\hline 8-Given a bad grade as a punishment & 85 & 89.5 & 4 & 4.2 & 6 & 6.3 & 108.9 & $.000 * *$ \\
\hline $\begin{array}{l}\text { 9-Hostility after or failure to acknowledge significant } \\
\text { clinical, research or academic accomplishment }\end{array}$ & 40 & 42.1 & 19 & 20 & 36 & 37.9 & 10.7 & $.030 *$ \\
\hline 10-Threats of violence or physical abuse or actual abuse & 28 & 29.4 & 7 & 7.4 & 60 & 63.2 & 27.2 & $.000 * *$ \\
\hline 11-Being ignored and excluded or socially isolated & 24 & 25.3 & 14 & 14.7 & 57 & 60 & 25.2 & $.000 * *$ \\
\hline 12-Unmanageable workloads or unrealistic deadlines & 64 & 67.4 & 12 & 12.6 & 19 & 20 & 98.7 & $.000 * *$ \\
\hline $\begin{array}{l}\text { 13-Intimidating behavior such as finger-pointing, invasion of } \\
\text { personal space, shoving, blocking/barring the way }\end{array}$ & 25 & 26.3 & 38 & 40 & 32 & 33.7 & 38.7 & $.000^{* *}$ \\
\hline
\end{tabular}

** Significant at $\mathrm{p}<0.001$

* Significant at $\mathrm{p}<0.05$

Table (2) shows that the negative acts as experienced by the students' nurses

Were highly frequent to subtitle item assignments, task, work or rotation responsibilities made for punishment rather than educational purposes, threats of violence or physical abuse or actual abuse and being ignored and excluded or socially isolated were $69.5 \%, 63.2 \%$ and $60 \%$ respectively. While $100 \%$ were not frequent to subtitle negative and disparaging remarks about nursing's profession.

Third section: Frequency of exposure to bullying behaviors as experienced by the studied student nurses.

Table (3) a. Distribution of studied student nurses according to their frequency of exposures to Bullying Behaviors

\begin{tabular}{|c|c|c|c|c|c|c|c|c|c|}
\hline & \multirow[t]{3}{*}{ Bullying Behaviors } & \multicolumn{6}{|c|}{ Nursing students $(\mathrm{N}=95)$} & \multirow{3}{*}{$\begin{array}{l}\text { Chi- } \\
\text { squar } \\
\text { e }\end{array}$} & \multirow[t]{3}{*}{ p-value } \\
\hline & & \multicolumn{2}{|c|}{ Not frequent } & \multicolumn{2}{|c|}{ Frequent } & \multicolumn{2}{|c|}{ Highly frequent } & & \\
\hline & & No. & $\%$ & No. & $\%$ & No. & $\%$ & & \\
\hline 1 & Threats of physical violence & 26 & 27.4 & 33 & 34.7 & 36 & 37.9 & 26.4 & $.000 * *$ \\
\hline 2 & Intimidated with disciplinary measures & 49 & 51.6 & 34 & 35.8 & 12 & 12.6 & 11.9 & .007 \\
\hline 3 & Threatened with a poor evaluation & 70 & 73.7 & 11 & 11.6 & 14 & 14.7 & 49.4 & $.000 * *$ \\
\hline 4 & Impossible expectations were set for me & 80 & 84.2 & 9 & 9.5 & 6 & 6.3 & 91.8 & $.000 * *$ \\
\hline 5 & Inappropriate jokes were made about me & 46 & 48.5 & 14 & 14.7 & 35 & 36.8 & 4.4 & .35 \\
\hline 6 & Malicious rumors were spread about me & 62 & 65.2 & 22 & 23.2 & 11 & 11.6 & 46.6 & $.000 * *$ \\
\hline 7 & Unjustly criticized & 70 & 73.7 & 19 & 20 & 6 & 6.3 & 56.9 & $.000^{* *}$ \\
\hline 8 & Information was withheld from me purposefully & 90 & 94.7 & 3 & 3.2 & 2 & 2.1 & 103.4 & $.000 * *$ \\
\hline 9 & $\begin{array}{l}\text { Attempts were made to be little/undermine my } \\
\text { work }\end{array}$ & 49 & 51.6 & 34 & 35.8 & 12 & 12.6 & 10.8 & $.013^{*}$ \\
\hline 10 & Treated poorly on grounds of race & 76 & 80 & 19 & 20 & 0 & 0 & 16.7 & $.000^{* *}$ \\
\hline 11 & Treated poorly on grounds of disability & 56 & 58.9 & 39 & 41.1 & 0 & 0 & 4.8 & 0.09 \\
\hline 12 & Treated poorly on grounds of gender & 36 & 37.9 & 35 & 36.8 & 24 & 25.3 & 2800 & .247 \\
\hline 13 & Expectation of work were changed without notice & 49 & 51.6 & 38 & 40 & 8 & 8.4 & 30.2 & $.000 * *$ \\
\hline
\end{tabular}

Table (3) b. Distribution of studied student nurses according to their frequency of exposures to Bullying

Behaviors

\begin{tabular}{|c|c|c|c|c|c|c|c|c|c|}
\hline & \multirow[t]{2}{*}{ Bullying Behaviors } & \multicolumn{6}{|c|}{ Nursing students $(\mathrm{N}=95)$} & \multirow[t]{2}{*}{ Chi-square } & \multirow[t]{2}{*}{ p-value } \\
\hline & & \multicolumn{2}{|c|}{ Not frequent } & \multicolumn{2}{|c|}{ Frequent } & \multicolumn{2}{|c|}{ Highly frequent } & & \\
\hline 14 & $\begin{array}{l}\text { Responsibilities were removed without } \\
\text { warning }\end{array}$ & 48 & 50.6 & 33 & 34.7 & 14 & 14.7 & 8.9 & $0.030 *$ \\
\hline 15 & $\begin{array}{l}\text { Placed under undue pressure to produce } \\
\text { work }\end{array}$ & 34 & 35.8 & 46 & 48.4 & 15 & 15.8 & 36.3 & $.000 * *$ \\
\hline 16 & Physically abused & 91 & 95.8 & 4 & 4.2 & 0 & 0 & 39.8 & $.000 * *$ \\
\hline 18 & Treated with hostility & 83 & 87.4 & 12 & 12.6 & 0 & 0 & 20.2 & $.000 * *$ \\
\hline 19 & Attempts were made to demoralize me & 68 & 71.5 & 20 & 21.1 & 7 & 7.4 & 29.7 & $.000 * *$ \\
\hline 20 & Teased & 37 & 38.9 & 34 & 35.8 & 24 & 25.3 & 10.3 & $.016^{*}$ \\
\hline 21 & Efforts were undervalued & 75 & 78.9 & 8 & 8.5 & 12 & 12.6 & 35.7 & $.000^{* *}$ \\
\hline 22 & Humiliated in front of others & 45 & 47.4 & 38 & 40 & 12 & 12.6 & 23.5 & $.000 * *$ \\
\hline 23 & Resentment towards me & 67 & 70.5 & 25 & 26.3 & 3 & 3.2 & 32284 & $.000 * *$ \\
\hline
\end{tabular}


Table (3) (a and b) shows that the bullying behaviors experienced by the students nurses were highly frequent to subtitle item as threats of physical violence, inappropriate jokes were made about me and teased were $37.9 \%$, $36.8 \%$ and $25.3 \%$ respectively. While $95.8 \%$ were not frequent to subtitle physically abused.

Fourth section: Correlations between Assignments, task, Threats of physical violence and Academic achievements

Table (4) Correlations between Assignments, task, Threats of physical violence and Academic achievements

\begin{tabular}{|l|l|l|}
\hline Item & \multicolumn{2}{|l|}{ Academic achievements } \\
\cline { 2 - 3 } & $\mathbf{R}$ & $\mathbf{P}$ \\
\hline $\begin{array}{l}\text { Assignments, task, work or rotation responsibilities made for punishment rather than } \\
\text { educational purposes }\end{array}$ & 2.227 & .898 \\
\hline Threats of physical violence & & \\
\hline
\end{tabular}

Table (4) Correlations between assignments, task, Threats of physical violence and Academic achievements were not significant.

\section{Discussion}

Because today's students are tomorrow's colleagues, conversations regarding how to address bullying should include specific aspects of nursing academia and the preparation of new nurses (16).In this regard, several studies that involving nursing students found that bullying and harassment at nursing education is an important problem and that such bullying behaviors have detrimental effects. And $(\mathbf{1 7}, \mathbf{1 8})$. Also it is quoted that nursing students have the highest risk of experiencing aggression because of inexperience, frequent ward changes and the challenge of meeting new environments (19). Although The World Health Organizations, the International Council of Nurses, and Public Services International recognize the incidence of violent episodes as a major health priority, the number of nurses affected by this problem still continues to rise $(\mathbf{2 0 , 1 1 ) .}$

This descriptive study was conducted at nursing college and allied health sciences, Jazan University and aimed to investigate vertical violence encountered by the nursing students throughout their clinical learning in health care settings. The present study revealed that slightly more than half of the studied participants were trained in diagnostic units in private hospitals. Slightly less than half of these participants exposed to violence from two to three times during their period of clinical training. This is explained by the assumption that, the nursing students have the highest risk of experiencing aggression because of inexperience, frequent ward changes and the challenge of meeting new environments (21). This finding is also supported by (22) who mentioned that the prevalence of subjects reporting at least one upsetting episode of physical or verbal violence during their lifetime activity in clinical settings was $43 \%$ in nurses and $34 \%$ in nursing students. The rate is even lower compared with the rate reported by (1) $85.2 \%$ of participants had been subjected to at least one kind of violence .On the contrast; the study that conducted by (23) revealed that high percent of students $66 \%$ never exposure to threats of violence or physical abuse or actual abuse. The result of present study is in agreement of the findings of previous Turkish study of (24) which found that $50.3 \%$ of the students were subjected to violence in the clinical settings. In this regard, many nursing researchers maintained that inappropriate and unprofessional behaviors in nursing are common and widespread across all clinical settings and in many healthcare environments (25). Regarding reason for violence, about half of the studied participants were subjected due to their lack of effective communication skills with others. This is quite expected because of the nursing students are particularly vulnerable when entering this kind of workplace, they are often younger, have less clinical and life experience, fewer acquired coping skills, minimal power in the environment's hierarchy (26) .and are unfamiliar with the environment and its standards (27).

Concerning the person who inflicting violence; about half of the participants reported that the doctors were most often responsible for the violence as perceived by them. This is explained that student nurses face a greater likelihood of exposure to violence from patients and visitors. On the other hand, they are also exposed to experiencing and perceiving on-the-job abuse from other healthcare workers (11).Within the same context, in study of Workplace Violence against Nursing Students and Nurses: An Italian Experience done by (10). found that nurses were prevalently exposed to "external" violence, that is, physical or verbal violence from patients or their relatives and friends (94\% and $71 \%$, respectively), while students often reported both verbal and physical violence from colleagues, staff, and others, who included teachers, doctors, and supervisors. "Internal" violence accounted for $41 \%$ of physical and $76 \%$ of non- physical assaults against students. Moreover, the study result is in agreement with (23) who mentioned that nearly less than half of student exposure to Negative and disparaging remarks about nursing's profession by physician. This may due to increase load on nurses, physician in the hospital and faculty employees also miscommunication between them. Also (28) found that primarily physicians, then patients, and patients' families were responsible for most of the verbal abuse towards nurses. Moreover, in a British study, around 35\% of students reported having been bullied; and around one in four of the 1,000 students questioned said they had been bullied by a doctor, while one in six had been bullied by a nurse (27). 
The finding of this study clarified that the negative acts as experienced by the students' nurses were highly frequent to subtitles related to item assignments, task, work or rotation responsibilities made for punishment rather than educational purposes, threats of violence or physical abuse or actual abuse and being ignored and excluded or socially isolated were $69.5 \%, 63.2 \%$ and $60 \%$ respectively. It can be explained nursing students reported that work related bullying was the most annoying problem for them it is possible that students in general do not understand assignments, workload and deadlines as a consequence of the learning environment. This is in constant with (29). as in their finding were work related bullying (e.g., assignments, task or rotation responsibilities made for punishment rather than educational purposes) was the most frequently encountered type of bullying behaviors, $34.80 \%$ in total, followed by personal related bullying (e.g., being shouted, spreading gossip, socially isolated), $23.22 \%$ in total. While, in contrast to the current study result, only very small amount of respondents (only $2.43 \%$ ) reported physical intimidating forms of bullying (e.g., threats of violence or physical abuse, intimidating behavior such as finger pointing). This is in accordance with the study result of (23) who found that high percent of students $66 \%$ never exposure to threats of violence or physical abuse or actual abuse. Meanwhile, the studied participants were not frequent exposed to negative and disparaging remarks about nursing's profession. And, this result is in contrast with also result of the study done by (23). who reported that high percent $43 \%$ of students always exposure to behavior of Negative and disparaging remarks about nursing's profession. Moreover (29) .found that; one of most common bullying behaviors reported by the studied participants was "negative and disparaging remarks about nursing's profession" $(11.85 \%)$.

The finding of the study showed that the bullying behaviors experienced by the students' nurses were highly frequent to subtitle item as threats of physical violence, inappropriate jokes were made about me and teased were $37.9 \%, 36.8 \%$ and $25.3 \%$ respectively. Conversely (15). found that the least frequent negative behavior selected by the students was the threat of actual physical violence which was reported by $2.5 \%$ of the sample. Additionally (30). pointed out that 87 students (12.91\%) reported having been threatened with physical harm. Within the context, the study done by (31). concluded that; one of the most frequently reported bullying behaviors by second year students was being teased $(82.6 \%)$. Meanwhile, $95.8 \%$ were not frequent to subtitle physically abused. This is in agreement with the study done by (31).who, mentioned that the least reported bullying behaviors were: treated poorly on grounds of disability (1.3\%); then equal percentage for both treated poorly on grounds of race, and physically abused $(1.8 \%)$ each.

The result of this study indicated that the correlations between assignments, task, Threats of physical violence and Academic achievements were not significant. It can be explained that; this finding could be related to about half of studied participants trained for about two months, three fourth of them were at the fourth grade in addition to majority of them also had academic average ranged between good to very good. For these reasons; most of the studied participants can deal efficiently with academic work during their clinic course with ability to confront most issues in spite of encountering to threat of physical violence, assignments, task, work or rotation responsibilities made for punishment rather than educational purposes. This finding is in agreement with a study of 433 Danish manufacturing employees which found no association between exposure to bullying behaviors and self-efficacy (32). Whereas, self-efficacy can be improved by individual success in achieving the desired outcomes, seeing others achieve success by inspirational speeches, and by declining the outcomes, being encouraged, thankful and motivated anxiety level $(\mathbf{3 3}, \mathbf{3 4})$. Thus, when students involve themselves in academic tasks, internal and external opinions lead to either an increase or decrease in self-efficacy. Meanwhile, this finding disagreed with (35) who found that there was a significance relationship between bullying behavior and general self-efficacy among the studied nursing students. In this regard, (36) added that, bullying makes new nurses feel invisible, incompetent, and inferior and suppresses their initiative and innovation. Moreover, (23)founded that, more than half of students who experienced bullying behaviors occasionally exposed to diminishing performance, becoming forgetful, losing confidence and decreasing their concentration.

\section{Conclusion}

Results of this study indicate that nearly half of the studied nursing students were encountered to violence during their clinic course for two to three times due to their lack of effective communication skills. With high frequency of exposure to negative acts as assignments, task, work or rotation responsibilities made for punishment rather than educational purposes, threats of violence or physical abuse or actual abuse and being ignored and excluded or socially isolated. Also; with high frequency of exposure to bullying behaviors as threats of physical violence, inappropriate jokes were made about me and teased. However, there were not significant correlation between assignments, task, threats of physical violence and academic achievements of the participants. 


\section{Recommendation}

The current study recommends that nursing students must be prepared before they attend clinical environment to empower them with effective communication skills to deal with common issues and respond professionally with negative encounters In addition to, continuous presence \& supervision, of clinical instructors, where support and positive reinforcement is provided for the nursing students in a nonthreatening clinical environment.

\section{References}

[1] Talas,M,Kocaoz,S. and Akguc,S. (2011): A survey of violence against staff working in the emergency department in Ankara , Turkey,Asian .Nursing research 5(2011)197-203.

[2] Tomas,S, Junior Nursing Students experiences of vertical violence during clinical rotation (2009): University of TennesseeKnoxville,Sthomas @utk.edu.Nursing publication.

[3] Canty,S. Vertical violence and student nurse is this toxic for professtional identity development? (2012): Universty of Southern Mississippi , The Aquila Digital Community.

[4] Thomas, SP.Transforming Nurses Stress and Anger(2004) : Steps toward healing .New York, Ng . Springer.

[5] Shoghi,M,. Sanjari,M,. Shiraz,F,. Heldari,S,. Salemi,S., and Mirazabeigi,G.(2008) : Workplace violence and abuse against nurses in hospitals in Iran.Asian Nursing Research (2) 184-193.

[6] Cantey SW. (2013). Recognizing and stopping the destruction of vertical violence. Am Nurs Today, 8(2). Retrieved from http://www.medscape.com

[7] Freire P,. Pedagogy of the oppressed. New York, Ny. Continum,(2000).

[8] Hutchinson,M, Jockson,D, Vichers,M,Wilkes ,L(2006):P Workplace bullying in Nursing toward a more critical organizational prespective, Nurse Inq. 13:118-1026.

[9] Robert ,SJ.(2000): Developing a positive professional identity Lierary oneself from the oppressor with in ,Advance Nursing Sciences. 22:71-82.

[10] Magnavita, N., Heponiemi, T. (2011):Workplace violence against nursing students and nurses: an Italian experience. Journal of Nursing Scholarship. 43(2): 203-210. PMid:21605325 http://dx.doi.org/10.1111/j.1547-5069.2011.01392.x

[11] Kuehn, B.M. Violence in health care settings on rise.(2010): Journal of the American Medical Association. 2010; 304(5): 511-512. PMid:20682926 http://dx.doi.org/10.1001/jama.2010.1010

[12] Cooper, J.R.M., Walker, J.T., Askew, R., Robinson J.C., McNair M.(2011): Students` perceptions of bullying behaviors by nursing faculty. Issues in Educational Research.21(1): 1-21.

[13] Celik, S.S., and Bayraktar, N.(2004): A study of nursing student abuse in Turkey. Journal of Nursing Education. 43(7): 330-336.

[14] Keely, B.R.(2002): Recognition and prevention of hospital violence. Dimensions of Critical Care Nursing. 21 (6): 236-24. Stevenson, K., Randle, J., \& Grayling, I.

[15] (2006): Inter-group conflict in health care: UK students' experiences of bullying and the need for organizational solutions. The Online Journal of Issues in Nursing, 11(2), 5-6.

[16] Luparell, S. (2011). Incivility in nursing: The connection between academia and clinical settings. Critical Care Nurse, 31(2), 92-95. Lyneham, J. (2000). Violence in NSW emergency departments. Australian Journal of Advanced

[17] Magnavita, N., Heponiemi, T. (2011):Workplace violence against nursing students and nurses: an Italian experience. Journal of Nursing Scholarship. 43(2): 203-210. PMid:21605325 http://dx.doi.org/10.1111/j.1547-5069.2011.01392.x

[18] Magnussen, L., Amundson, M. J.(2003): Undergraduate nursing student experience. Nursing and Health Sciences. 5: 261-267. PMid:14622377 http://dx.doi.org/10.1046/j.1442-2018.2003.00158.x

[19] Ferns, T., and Meerabeau, L. (2007):Verbal abuse experienced by nursing students. Journal of Advanced Nursing. 61(4): 436-444. PMid:18034811

[20] Hinchberger, P.A.(2009): Violence against female student nurses in the workplace. Nursing Forum. 44(1): 37-46. PMid:19187052 http://dx.doi.org/10.1111/j.1744-6198.2009.00125.x

[21] Ferns, T., \& Meerabeau, L. (2007):Verbal abuse experienced by nursing students. Journal of Advanced Nursing, 61(4), 436-444. PMid: 1803481

[22] Magnavita, N., Heponiemi, T. (2011):Workplace violence against nursing students and nurses: an Italian experience. Journal of Nursing Scholarship. 2011; 43(2): 203-210. PMid:21605325 http://dx.doi.org/10.1111/j.1547-5069.2011.01392.x

[23] Basal,A.A., Elhossiny,E.A.(2014): Students' Perception and Experience of Bullying Behavior in the Faculty of Nursing. Journal of Nature and Science ;12(1) http://www.sciencepub.net/nature

[24] Celebioglu A., Akpinar R.B., Kucukoglu, and Engin R.(2010): Violence experienced by Turkish nursing students in clinical settings: their emotions and behaviors. Nurse Education Today.30: 687-691. PMid:20129722 http://dx.doi.org/10.1016/j.nedt.2010.01.006

[25] Woelfle, C. Y., \& McCaffry, R. (2007):Nurse on nurse. Nursing Forum. 42(3): 123-131.http://dx.doi.org/10.1111/j.1744 6198.2007.00076.x

[26] Dellasega, C.A. (2009): Bullying among nurses. American Journal of Nursing, 109(1), 52-58. doi: 10.1097/01.NAJ.0000344039.11651.08.

[27] Andrews, G.J., Brodie, D.A., Andrews, J.P., Wong, J., \& Thomas, B.G. (2005): Place(ment) matters: Students' clinical experiences and their preferences for first employers. International Nursing Review, 52, 142-153.

[28] Sofield, L., \& Salmond, S. W. (2003):Workplace violence: A focus on verbal abuse and intent to leave the organization. Orthopedic Nursing, 22(4), 274-283.

[29] Palaz,S.(2013): Turkish nursing students' perceptions and experiences of bullying behavior in nursing education. Journal of Nursing Education and Practice, January Vol. 3, No. 1

[30] Clarke, C., Kane, D., Rajacich, D., \& Lafreniere, K. (2012): Bullying in Undergraduate Clinical Nursing Education. Journal of Nursing Education, 51(5), 269-276.

[31] Abd El Rahman,R.M.(2014):Perception of Student Nurses' Bullying Behaviors and Coping Strategies Used in Clinical Settings

[32] Mikkelsen, E., G., and Einarsen, S. (2002): Relationships between exposure to bullying at work and psychological and psychosomatic health complaints: The role of state negative affectivity and generalized self-efficacy. Scandinavian Journal.

[33] Bandura, A. (1986): Social foundations of thought and action: A social cognitive theory. Englewood Cliffs, NJ: Prentice Hall.

[34] Jackson, J.,W. (2002): Enhancing self-efficacy and learning performance. The Journal of experimental Education, 70(3), 243-250.

[35] Kassem, A.H., Elsayed ,R.S., Elsayed ,W.A.(2015): Bullying Behaviors and Self Efficacy among Nursing Students at Clinical Settings: Comparative Study. Journal of Education and Practice. Vol.6, No.35,

[36] Townsend, T. (2012): Break The Bullying Cycle. American Nurse Today 7(1): available at www.AmericanNurseToday.com. 